\section{SOME ASPECTS OF THE PATHOLOGY OF ANAEMIA}

\section{INVESTIGATION OF CASTLE'S HYPOTHESIS*}

BY

L. J. WITTS, C.B.E., M.A., M.D., Sc.D., F.R.C.P. Nuffield Professor of Clinical Medicine, the Radcliffe Infirmary, Oxford

By 1932 Castle's hypothesis that pernicious anaemia was due to the absence of an intrinsic factor in the gastric juice which reacted with an extrinsic factor in the diet to produce the haemopoietic factor had been generally accepted. There were still, however, certain reservations. There was doubt whether complete loss of the stomach in man inevitably led to pernicious anaemia, for it did not do so in animals, and at that time there were few patients whose life had been prolonged more than a year or so after total gastrectomy. As the number of survivors has grown we have learned that pernicious anaemia always develops if the patient lives long enough, though it may take several years for the body to exhaust its stores of vitamin $B_{12}$ (Paulson and Harvey, 1954).

Another difficulty was that achlorhydria was thought to be quite common, 20 to $30 \%$ in the later age-groups after a single body-dose of histamine (Polland, 1933). Estimation of intrinsic factor by the Castle test was a long and arduous procedure, not without danger to the patients used as test subjects, so that no large series of individuals with achlorhydria but without pernicious anaemia was studied. Since the introduction of the augmented histamine test and similar methods of giving a maximal stimulus to the parietal cells we know that true achlorhydria occurs much less often than used to be believed and is always evidence of disease of the stomach (Witts, 1959). Of the patients with complete achlorhydria a moiety will also have lost their ability to secrete intrinsic factor (Callender, Retief, and Witts, 1960). The total number of such cases seems relatively large in relation to the prevalence of overt pernicious anaemia (Witts, 1960). Nevertheless, it is doubtful whether we need invoke any other factor than the exhaustion of the tissue reserves of vitamin $B_{12}$ to explain the transition from larval to overt pernicious anaemia.

\section{Stalemate and Break-through}

It would not be true to say that research based on Castle's hypothesis languished during the fifteen or twenty years after his first publications. Indeed, a good deal of exciting work was done to which I shall refer. Nevertheless, so long as neither extrinsic factor nor intrinsic factor had been characterized chemically the pace was slow. The doubts which I have mentionedwhether Castle's hypothesis provided a complete explanation of pernicious anaemia, and the failure to produce pernicious anaemia in animals by gastrectomy -led to the supposition that achlorhydria and loss of intrinsic factor might merely set the stage for pernicious anaemia but that some other factor was necessary for its complete development, an idea which, as I have just hinted, has not yet been completely abandoned.

Thus interest was revived in the long-mooted possibility of an intestinal factor in pernicious anaemia,

*The second of two Lumleian Lectures delivered before the Royal College of Physicians of London on April 11 and 13, 1961. The first lecture appeared in last week's issue and a series of clinical and experimental observations led to the recognition of a group of anaemias associated with stenosis, anastomosis, and massive diverticulosis of the small intestine which we now know to be due to impairment of absorption of vitamin $\mathbf{B}_{12}$ (Faber, 1895 ; Cameron, Watson, and Witts, 1949 ; Badenoch, 1960). Much of the experimental work was done on the rat, and when Watson and Florey (1955) subsequently demonstrated the value of the gastrectomized rat in the study of the absorption of vitamin $B_{12}$ we found that we had come back full circle to pernicious anaemia itself, and what Castle (1959) has called the years of the rat had begun in research on pernicious anaemia.

The isolation of folic acid in 1943 simplified our problems by indicating that there was a range of megaloblastic anaemias, usually of nutritional or intestinal origin, which were due to lack of folic acid and not of the liver principle active in pernicious anaemia, but by and large folic acid has not proved an easy tool to use in the investigation of the anaemias (Girdwood, 1960). The nature of the folic acid activity normally present in human serum and plasma, and its assay, are still under investigation (Herbert, 1961). We cannot estimate the tissue levels of folic acid in the same simple way that we can estimate the level of ascorbic acid in the white-cell layer of the blood. Tests dependent on the excretion of doses of folic acid in the urine or the clearance of folic acid from the plasma are indirect and difficult to interpret. Quite early on we came to the conclusion in Oxford that the way to the assessment of the folic acid status of the organism did not lie in this direction, and though some elegant work has since been done by others it has not changed our opinion (Spray, Fourman, and Witts, 1951; Spray and Witts, 1953). This is not to deny that Girdwood's (1953) test, which depends on comparing the amounts of folic acid excreted after subcutaneous injection and oral ingestion, has proved useful in the investigation of steatorrhoea.

The situation has not been radically altered by the introduction of tritiated folic acid-that is, folic acid in which some of the hydrogen atoms have been replaced by the radioactive isotope tritium (Johns, Sperti, and Burgen, 1961). The most useful method at present is one which depends on the role of folic acid in metabolism. There is evidence that formiminoglutamic acid (F.I.G.L.U.), an intermediate in the metabolic breakdown of histidine, accumulates in the urine of men and animals which are deficient in folic acid (Broquist, 1956 ; Silverman, Gardiner, and Condit, 1958). At first F.I.G.L.U. could be estimated only by complicated microbiological methods, and results, though encouraging, were slow in coming forward (Spray and Witts, 1959). However, the introduction of a relatively simple electrophoretic method of estimation (Knowles, Prankerd, and Westall, 1960) has changed all this, as radically as the electrification of a railway line changes a quiet suburb; we can look forward to a spate of papers on F.I.G.L.U.

The big surge forward in the study of the megaloblastic anaemias came with the isolation of vitamin $B_{12}$ in 1948, the associated discovery of microbiological methods of estimating the level of vitamin $B_{12}$ in the serum, and the subsequent labelling of the vitamin $B_{13}$ molecule by the incorporation of radioactive cobalt so that it could be used in tracer studies of the absorption and metabolism of vitamin $\mathbf{B}_{12}$. At one blow two unknowns had been eliminated in the equation $f+g=h$, which was based on the assumption that a food factor 
(f) reacted with a gastric factor (g) to give rise to a haemopoietic factor $(h)$, and the stage was set for the characterization of the intrinsic factor $(\mathrm{g})$. The way was finally open to a rational classification of the megaloblastic anaemias (Witts, 1956). They can be divided vertically, according as they are due to deficiency of vitamin $B_{12}$, folic acid, or both; or they can be divided horizontally, at the level of the cause of the deficiency - diet, stomach (in avitaminosis $\mathrm{B}_{12}$ only), intestine, or the organism itself in the relative deficiencies of folic acid which may sometimes be observed in pregnancy, idiosyncrasy to barbiturates, and pathologically accelerated blood formation (Chanarin, Dacie, and Mollin, 1959).

\section{Intrinsic Factor}

When I surveyed the material which I had collected for these lectures, I found that there were far more references to papers on intrinsic factor than on any other topic. This was not because there had been a greater accumulation of knowledge about intrinsic factor than, say, the antianaemic factor, but rather the reverse. Indeed, it is a common experience, as inspection of the bulky literature on blood coagulation will confirm, that when biologists and clinical scientists carry out researches with substances whose purity and chemical characteristics are not known, much of their work is likely to be inconclusive. Had research been centrally planned, it is certain that a much greater effort would have been put into the isolation of intrinsic factor. Fortunately there have been a number of reviews of this copious literature, of which Gräsbeck's (1960) is one of the most recent and comprehensive.

The isolation of vitamin $\mathbf{B}_{12}$, or cyanocobalamin, led to the hypothesis that intrinsic factor acts as a carrier in the absorption of vitamin $B_{12}$. When pure vitamin $B_{12}$ became available in quantity it was discovered that there are two mechanisms of absorption. If vitamin $\mathbf{B}_{12}$ is administered in milligram quantities a small percentage of the dose, usually quite enough to maintain health, is absorbed without intrinsic factor. This is presumably achieved by mass action, though the details of the process are not known. At any rate this mechanism is effective in pernicious anaemia and total gastrectomy. Absorption can occur by the same mass action through the oral, nasal, respiratory, and rectal mucosae. If vitamin $B_{12}$ is administered in microgram quantities, such as are present in the diet, intrinsic factor is necessary for its absorption, and little or none is absorbed in pernicious anaemia or after total gastrectomy.

When physiological doses ( 0.5 to $2 \mu \mathrm{g}$.) of radioactive vitamin $B_{12}$ of high specific activity are given to normal people or are given along with intrinsic factor to patients with pernicious anaemia, little or no radioactivity can be detected in the plasma within the first four hours of the test and the peak concentration occurs at eight to twelve hours. If an oral dose of 50 to 300 $\mu \mathrm{g}$. of radioactive vitamin $B_{12}$ is given in pernicious anaemia there is an entirely different curve, with an early rise in radioactivity in the plasma and a peak concentration usually at three to six hours. The watershed between the physiological and the pharmacological channels of absorption is probably round about a level of $50 \mu \mathrm{g}$. of vitamin $\mathbf{B}_{12}$. It has not yet been proved that all the cyanocobalamins require intrinsic factor for their absorption, but suggestions that the vitamin $B_{12}$ conjugates present in liver, or vitamin $B_{12}$ peptides, can be absorbed without intrinsic factor have not yet been substantiated.

Perhaps it would be better to call these different dose levels normal and supernormal rather than physiological and pharmacological, for rabbits normally ingest an amount of vitamin $B_{12}$ which would be supernormal in man. The rabbit obtains its vitamin $B_{12}$ by eating its faeces, particularly the soft faeces which are passed at night and which are especially rich in vitamin $B_{12}$. The quantity ingested daily represents the equivalent of 500 $1,500 \mu \mathrm{g}$. or more in man, and the level of vitamin $\mathbf{B}_{12}$ in the serum of the rabbit can be as much as 150 times higher than in man (personal communication, Mrs. K. I. Simnett and Dr. G. H. Spray). The vitamin $B_{12}$ in the faeces is produced by the action of bacteria on the food residues. The rabbit, if gifted with speech, would doubtless say that its coprophagy is an example of the process described by Platt and Webb (1946) as the ennoblement of food, and it can hardly be called unphysiological.

The delayed peak in the absorption of physiological doses of vitamin $B_{12}$ is due to temporary storage of the vitamin in the wall of the small intestine. Next it passes into the circulation and is found in more or less equal concentration in the liver, spleen, and kidneys 24 hours after ingestion. There is then redistribution with accumulation of the vitamin in the liver, a phenomenon which is used in Glass's test for the diagnosis of pernicious anaemia (Doscherholmen and Hagen, 1959 ; Doscherholmen, Finley, and Hagen, 1960). The turnover of vitamin $\mathbf{B}_{12}$ is slow, and in long-term experiments only 0.2 to $0.3 \%$ of the total amount of radioactive vitamin $B_{12}$ contained in the body is excreted per day. The half-life of a tracer dose in the liver is of the order of twelve months.

Vitamin $B_{12}$ is excreted in the bile, but much of this excreted material is reabsorbed, so that there is a closed enterohepatic circulation (Gräsbeck, Runeberg, and Simons, 1959). A break in this enterohepatic circulation is an important factor in the depletion of the body of vitamin $\mathbf{B}_{12}$ in pernicious anaemia and after gastrectomy, because intrinsic factor is needed for the reabsorption of the vitamin $B_{12}$ of the bile. Dr. G. H. Spray and Miss Maureen Booth, working in our laboratory, have found that, whereas normal rats excreted $38 \%$ of a parenteral dose of radioactive vitamin $B_{12}$ in the faeces, gastrectomized rats excreted $58 \%$; the excretion returned nearly to normal in the gastrectomized rats when they were given rat gastric juice (personal communication).

\section{Nature of Intrinsic Factor}

Intrinsic factor is non-dialysable and easily destroyed by heat. It is inactivated by pepsin and some other proteolytic enzymes, and if gastric juice is to be preserved for study it should be neutralized and then frozen and kept in a deep freeze. The chemical nature of intrinsic factor is not yet known. Concentrates have been obtained of which as little as $0.3 \mathrm{mg}$. will ensure normal absorption of the dose of radioactive vitamin $\mathbf{B}_{12}$ used in the Schilling test or the faecal excretion test in patients with pernicious anaemia, and there is reason to believe that preparations active in a dose of $30 \mu \mathrm{g}$. could be obtained (Heatley, Sheikh, and Taylor, 1960). Intrinsic factor concentrates are prepared from the mucoprotein fraction of the gastric juice or mucosa, but it has not been established for certain that intrinsic factor itself is a mucoprotein (Ellenbogen and Williams, 1960). 
Intrinsic factor was originally studied in human gastric juice, and, though for many purposes it is convenient to use preparations from animal stomachs, these can be misleading, because intrinsic factor from different species may differ in site of production, activity in the same and different species, association with inhibitors, and tendency to produce refractory states. Human gastric juice and most preparations of hog intrinsic factor do not promote the absorption of vitamin $B_{12}$ in the gastrectomized rat, in contrast to homogenates of rat stomach and rat gastric juice. In isolated segments of rat intestine human gastric juice does not increase the uptake of vitamin $B_{12}$ (Abels, 1959). Moreover, it is possible to produce antibodies to intrinsic factor in animals (Taylor and Morton, 1958, 1959).

$A$ number of preparations in which vitamin $B_{12}$ is combined with concentrates of hog intrinsic factor for the oral treatment of pernicious anaemia have proved unsatisfactory and have shown a progressive decline in effect (Blackburn, Cohen, and Wilson, 1955). This loss of effect is due to a diminished ability of the patient to absorb vitamin $B_{12}$ under the influence of hog intrinsic factor (Schwartz, Lous, and Meulengracht, 1958). In patients in whom resistance has occurred it may be overcome by using human intrinsic factor or by giving massive doses of hog intrinsic factor (Berlin, Berlin, Brante, and Sjöberg, 1958). The mechanism underlying this development of resistance is not yet understood. Resistance does not occur on treatment with desiccated whole hog's stomach, and it does not develop with all commercial preparations of hog intrinsic factor (Wilkinson, 1949 ; Ellenbogen, Williams, and Lichtman, 1960).

\section{Mode of Action of Intrinsic Factor}

Transport of substances across membranes often requires a carrier which enables the substance to pass through the cell membrane and a receptor which holds it within the cell. This mechanism appears to apply to the absorption of vitamin $B_{12}$. The concept of the " binding" of vitamin $\mathbf{B}_{12}$ was introduced by Ternberg and Eakin (1949). They showed that normal gastric juice contains a component which combines stoichiometrically with vitamin $B_{12}$ to form a complex which is not dialysable or dissociated by dialysis and in which the vitamin $B_{12}$ is no longer available to bacteria. A good deal of confusion has been caused because many naturally occurring substances which do not have intrinsic factor activity can bind vitamin $B_{12}$. Nevertheless, ability to bind vitamin $B_{12}$ is one of the essential characteristics of intrinsic factor, and the most potent preparations of intrinsic factor so far made have a high binding capacity. Thus it seems clear that the absorption of vitamin $B_{12}$ is related to its binding to intrinsic factor which acts as a carrier.

Normal gastric juice can remove vitamin $B_{12}$ from beef muscle and casein in vitro, and this is probably the first step in the absorption of vitamin $B_{12}$ from the food (Cooper and Castle, 1960). The presence of $\mathrm{HCl}$ facilitates the binding of intrinsic factor with vitarnin $B_{12}$ in the stomach. The necessity for this early binding of vitamin $B_{12}$ is shown by some observations we have made on patients in whom the stomach has been completely bypassed in the treatment of peptic stricture of the oesophagus and the oesophagus joined to a Roux loop of jejunum (Callender, Witts, Allison, and Gunning, 1961) (see Fig.). Although much of the proper gastric gland area was intact and probably secreting, the patients had a gross defect in the absorption of vitamin $\mathbf{B}_{12}$ which could be corrected by the addition of intrinsic factor. The probability is that contact between intrinsic factor and vitamin $B_{12}$ was established too late for effective union between them to take place, either because the vitamin $B_{12}$ had already become bound to other substances or because conditions in the jejunum were unpropitious.

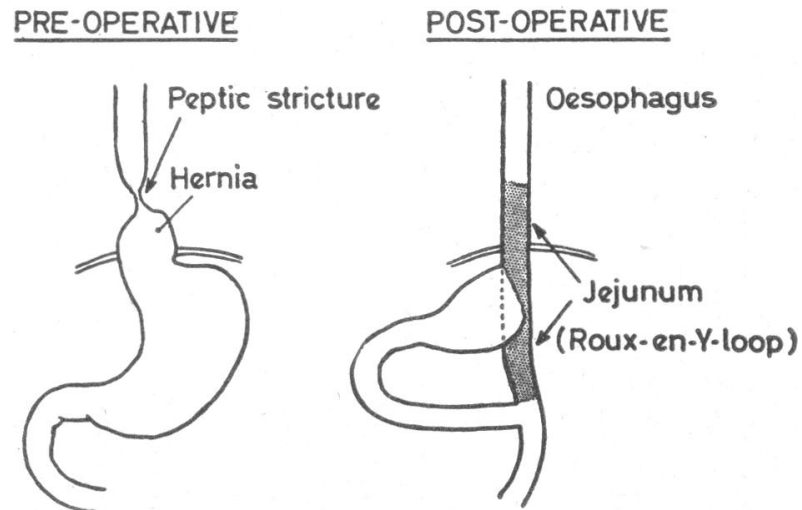

By-passing the stomach may produce avitaminosis $\mathbf{B}_{\text {, and }}$ megaloblastic anaemia even though the stomach itself is intact.

As long ago as 1938 Uotila found that the strength of the antianaemic activity of the dried defatted tissues of the gastro-intestinal tract of the pig appeared to decrease in the order pylorus, ileum, duodenum, jejunum, cardia, colon, and fundus. In modern terms this distribution would be explained on the hypothesis that in the pig intrinsic factor is secreted by the pyloric gland organ, and the complex of intrinsic factor with vitamin $B_{12}$ is absorbed in the ileum. Experiments in the rat suggested that the greatest absorption occurred in the second and third quarters of the small intestine (Reynell, Spray, and Taylor, 1957). In man both clinical observation of patients with resections and direct measurement of the distribution of radioactivity in the small intestine of patients during the absorption of ${ }^{56} \mathrm{Co}$ labelled vitamin $B_{12}$ indicate that the site of absorption of vitamin $B_{12}$ is the ileum (Booth and Mollin, 1959 ; Allcock, 1961).

The localization of the absorption of vitamin $B_{12}$ is probably determined by the presence of a specific receptor for it (Glass, Boyd, and Stephanson, 1954). We can think of intrinsic factor as an amboceptor with two combining groups, one of which links up with vitamin $B_{12}$ and the other with an acceptor in the cells of the ileum. The acceptor is apparently near the surface of the cell, for, although it can be temporarily saturated with the vitamin $B_{12}$ complex, it quickly clears itself and is ready to accept further vitamin $B_{12}$ long before the previously absorbed vitamin $B_{12}$ has passed into the blood-stream. Moreover, it can be temporarily blocked by intrinsic factor from a different species without promoting the absorption of vitamin $B_{12}$. The last stage of absorption is the passage of the intramural vitamin $B_{12}$ into the blood-stream, a process which requires time and probably the output of energy by the cell. It appears to be uninfluenced by the concentration of vitamin $B_{12}$ in the blood-stream. Whether the intrinsic factor also enters the blood-stream or is destroyed is not known.

\section{Site of Production of Intrinsic Factor}

Shortly after Castle had given his preliminary communication on intrinsic factor at the meeting of 
the American Society for Clinical Investigation in Washington in 1928, Sturgis and Isaacs (1929) in America and Wilkinson (1930) in England showed that desiccated stomach also was effective in the treatment of pernicious anaemia. Sturgis and Isaacs used fresh whole hog stomach which was desiccated so that $30 \mathrm{~g}$. of the dried substance was equivalent to $190 \mathrm{~g}$. of the fresh tissue. They believed that its potency was due to an enzymatic action of the intrinsic factor in the mucosa upon the muscular layer.

By cutting wedges of the entire thickness of the stomach - that is, mucous membrane plus muscular layer -from carefully chosen areas of the pig's stomach, Meulengracht (1934) showed that material from the pyloric gland area was highly active, but material from the body or proper gland area was inactive in pernicious anaemia. Preparations from the duodenum of the hog containing Brunner's glands were also active (Meulengracht, 1935). Preparations from the body had a high concentration of pepsin and rennin, while those from the pyloric gland area and the cardia contained very small amounts (Meulengracht and Schiødt, 1934). Hence the production of intrinsic factor is dissociated from that of pepsin and rennin in the pig.

Following on these early studies it has been clearly demonstrated that in the hog both pure pyloric secretion and pure duodenal secretion from the area of Brunner's glands contain intrinsic factor (Landboe-Christensen and Bohn, 1947 ; Landboe-Christensen and Wandall, 1953 ; Heatley, Jennings, Florey, Watson, Turnbull, Wakisaka, and Witts (1954). In the pig it is possible to strip the mucosa, together with its muscularis mucosae, from the muscular coat of the stomach (Meulengracht, 1952). Some confusion was caused by the fact that preparations from each of these two layers showed antianaemic activity. The explanation appears to be that the muscular layer always contains traces of intrinsic factor, derived in part from pyloric glandular tissue which has penetrated into the muscular layer and partly from diffusion of intrinsic factor into the muscular layer during the interval of several hours which elapses between killing the pig and making the preparations. The admixture need only be small ; Meulengracht (1953) showed that preparations made from 99 parts of hog uterus and one part of pyloric mucosa were active.

It would therefore seem that Sturgis and Isaacs were correct and that the antianaemic action of desiccated hog stomach is due to the interaction of intrinsic factor derived from the pyloric glands with vitamin $B_{12}$ which is present in both the mucosal and the muscular layers. Meulengracht (1939) associated the pyloric glands of the stomach and Brunner's glands of the duodenum together as the pyloric gland organ and suggested that pernicious anaemia was due to disease of this organ.

The hypothesis, though logical, was a disturbing one. Pernicious anaemia only rarely occurs after partial gastrectomy for peptic ulcer in man, though the aim of the surgeon is to eliminate the pyloric antrum; and Meulengracht (1939) himself showed that the pathological changes visible in the human stomach in pernicious anaemia were limited to the proper gastric gland area in the body and did not reach down into the pyloric gland organ. Moreover, Castle, Townsend, and Heath (1930) had produced some evidence that the duodenal juice in man does not contain intrinsic factor, and later work has supported them (LandboeChristensen and Bohn, 1947).
The next step was the application of Meulengracht's technique to apparently healthy human stomachs obtained at necropsy. Wilkinson, Klein, and Ashford (1938), who used whole stomachs incubated with beef, had already shown that the normal human stomach possessed intrinsic factor activity whereas the stomach of patients with pernicious anaemia did not. Fox and Castle (1942) showed that preparations obtained from the pyloric area in man were probably inactive in the treatment of pernicious anaemia, but preparations from the body and the cardia were fully active. Similar results were obtained by Landboe-Christensen and Plum (1948) and Meulengracht (1952). Further experiments by Landboe-Christensen, Berk, and Castle (1952) showed that preparations from the body of the human stomach possessed antianaemic activity, from the duodenum possessed weak activity, and the jejunum was inactive. The orthodox conclusion from these experiments is that, whereas in the pig intrinsic factor is produced by the pyloric gland organ, in man it is produced in the proper gastric gland area, and any activity demonstrated lower down is due to contamination or reabsorption.

\section{A Technical Dificulty}

Much of the early work on pernicious anaemia was marred by the inability or undesirability of submitting a sufficient number of patients with pernicious anaemia in relapse to test, and the result has often been the erection of a large superstructure of theory on an inadequate basis of fact. There are obvious objections to using, for therapeutic trials, human tissues obtained after death, even in these days of artery banks and corneal grafts. Nevertheless, it is wise to remember that in experiments of this type one man is equal only to one mouse, and the experiments reviewed above were insufficient in number and the results were not clear-cut. They were done by the Castle test, which is apt to be vitiated by spontaneous remissions and which has been superseded by the use of tracer doses of radioactive vitamin $B_{12}$ in patients with pernicious anaemia in remission. The preparations from the different parts of the human stomach and intestine were not made as a rule until 12 to 14 hours after death, and during this time intrinsic factor may well have diffused from its place of origin to other parts of the stomach or intestine. The impracticability of getting absolutely fresh material from human necropsies has probably been crucial in blocking this particular line of attack.

Further progress in this field may have to await technical improvements which will allow us to demonstrate intrinsic factor in human biopsy material. One of the difficulties is that there appear to be species differences in intrinsic factor, as already mentioned. Intrinsic factor derived from man or the pig is not effective in the gastrectomized rat, at any rate in crude preparations, while intrinsic factor derived from the rat is effective (Abels, 1959 ; Castle, 1959 ; Heatley, Sheikh, and Taylor, 1960). Landboe-Christensen and HoffJörgensen (1955) studied the ability of different portions of the mucosa to bind vitamin $B_{12}$, obtaining human material from cases of partial gastrectomy. In the pig the highest binding activity was found in the area of the pyloric gland organ, whereas in man the maximum binding activity was found in the body of the stomach. Human duodenal mucosa showed some activity. Unfortunately, ability to bind vitamin $B_{12}$ is not peculiar to intrinsic factor, and the fact that the highest activity found in man was only about 1 or $2 \%$ of the maximum 
found in the pig makes the localizing value of these experiments doubtful.

Meulengracht (1952) wrote that it would be inexplicable if secretion of the intrinsic factor in one species took place in the pyloric glands and in another species in the fundus glands; in fact, it would shake the foundations of all comparative physiology. The only animal other than man and the pig which has been fully studied is the rat, and here the state of affairs seems to be much the same as in man. In the rat the stomach consists of two parts-a proximal fore-stomach, which is lined by squamous epithelium, and a distal glandular portion. The latter consists of a body or proper gastric gland area and a pyloric area. Removal of the fore-stomach and the proper gastric gland area, leaving the pyloric area in situ, greatly reduces the absorption of vitamin $B_{12}$ and indeed has much the same effect as total gastrectomy. Administration of extracts of body mucosa restores absorption to normal but extracts of antrum are ineffective (Keuning, Arends, Mandema, and Nieweg, 1959).

Efforts to locate the site of production of intrinsic factor more closely and to discover the cells by which it is secreted have so far given inconclusive results. On the hypothesis that intrinsic factor is a mucoprotein or mucopolysaccharide, different areas of the stomach have been stained with the periodic-acid-Schiff (P.A.S.) stain, which reacts with polysaccharides. In man and rat the surface epithelium and the mucous neck cells of the body of the stomach give the P.A.S. reaction, but in the pig there is no correlation between the P.A.S. reaction and either antianaemic activity or the binding of vitamin $\mathbf{B}_{12}$.

The blood-group substances are present in high concentration in the mucosa of the stomach and duodenum. They are macromolecules which belong to the class of compounds known as mucopolysaccharides (Morgan and Watkins, 1959). Fluorescent antisera can be prepared from them and used in "staining" or locating the antigen in the tissues. The patterns of staining are complicated and differ in secretors and nonsecretors, but the blood-group substances are most easily demonstrated in the superficial cells of the stomach and to a smaller extent in the mucoid cells in the glands. Parietal cells may stain but not zymogenic cells (Glynn, Holborow, and Johnson, 1957). It is possible to concentrate material from gastric juice which has strong intrinsic-factor activity and which is free of blood-group substances, though it is probably not homogeneous material. The fluorescein technique has been employed with this material as the antigen in an attempt to locate the site of origin of intrinsic factor, using fresh human stomachs removed at operation, but apparently the intrinsic factor rapidly diffuses out of the cells, and so far it has not been possible to obtain sharp pictures (Drs. E. J. Holborow and K. B. Taylor, personal communication).

It may well be that the hypothesis that intrinsic factor is a mucoprotein or mucopolysaccharide is an ignis fatuus which has misled workers in this field. It is not supported by radioautographic studies which give the most persuasive results to date. In these experiments gastric mucosa from the rat was incubated with solutions of radioactive vitamin $B_{12}$ so that the radioactive vitamin $B_{12}$ might become bound to any intrinsic factor which was present, and the sections were then mounted and developed. The resultant blackening from radio- activity was limited to the mucosa of the body. The mucoid neck cells were completely devoid of radioactivity, which was confined to the deeper portions of the glands and was found exclusively in the chief or zymogenic cells (Keuning et al., 1959). The incompatibility between these observations in the rat and the complete separation of the secretion of intrinsic factor and pepsin in the pig is so great as to make one hesitate about their interpretation.

\section{Present Position of Castle's Hypothesis}

This review of more than 30 years' work since Castle's first publications shows that his hypothesis has stood the test of time as a satisfactory explanation of the pathological physiology of pernicious anaemia and has proved fruitful as a basis of research. There is still, however, a large defect in this field of knowledge. We do not yet know the chemical nature and structure of the intrinsic factor or factors, or the site of production, and this remains one of the most important unsolved problems in an area which is of common interest to the haematologist and the gastroenterologist.

\section{Conclusion}

The treatment of pernicious anaemia with liver was discovered by Minot and Murphy in 1926. The efficacy of iron in hypochromic anaemia and the appropriate dosage of ferrous and ferric salts were rediscovered about the same date. It might well have been thought that the problems of the deficiency anaemias were solved and clinical scientists should now pass on to other studies. Indeed, many did think so, and my friend Professor S. Alstead will perhaps forgive me for quoting some words he wrote in 1949:

"The discovery of the liver treatment of pernicious anaemia was not the outcome of logical deduction from physiological premises ; and to this extent the discovery comes into the class of happy accidents. Now the effect of this momentous discovery was the releasing of a vast number of workers on the whole subject of blood diseases and the physiology of blood formation. I do not maintain that this great effort has been in vain; but it is remarkable that when research takes on this form it dissipates itself over an enormous field, and any further advance comparable with the original discovery is rare. The researcher's attempts to predict new therapeutic advances from previous discoveries have nearly always proved disappointing. There is a further reason for choosing pernicious anaemia as an illustration. It is a comparatively rare disease ; and I feel most strongly that as research-workers we are excessively concerned with the minutiae of uncommon diseases while the common and disabling maladies receive far too little attention."

One need only mention vitamin $\mathbf{B}_{12}$, folic acid, and folic-acid antagonists to realize that the discovery of the therapeutic action of liver was far from exhausting the mine of information to be obtained from the study of pernicious anaemia, even in terms of treatment. But so long as we know only the treatment of a disease our work is but half done. Consider, for example, the life-history of diabetes mellitus, which is hardly yet completely elucidated nearly forty years after the isolation of insulin and which, though modified, has not been fundamentally changed by insulin. The layman 
is rightly more interested in prevention than treatment, and for this we must know the aetiology of a disease, which may well prove a complex genetic and environmental problem. And, finally, we must know the mechanism of symptoms. I have said some hard things in my time about phenomenology, but there is no doubt that the study of symptoms may give us power to control disease. A good example is the discovery of chlorothiazide, which would have been unlikely to be made if so many people had not been fascinated by the study of the symptom, oedema.

A disease is nature's experiment. I have compared it with a mine, a gold mine, for example, in which uranium is found by chance by men who seek for gold. I have also compared it, on another occasion, with the quinine molecule, which has preoccupied the German chemists and their successors since 1856, when W. H. Perkin, in attempting to prepare quinine from aniline, almost by accident discovered a new world of colour in the aniline dyes. Antipyrine and plasmoquine came directly from the study of the quinine molecule, and indirectly it was an inspiration in the search for chemical remedies for infectious disease which was to prove so successful in our time.

Finally, one can compare a disease like pernicious anaemia with a machine-tool. Although gastroenterology has advanced greatly on the observational side, it is still a laggard so far as the understanding and prevention of disease are concerned. To support this statement I need only recall how ineffective we are in the prevention and treatment of peptic ulcer, cancer of the stomach, regional ileitis, and ulcerative colitis. Clinical scientists, working on the anaemias, have forged new tools for the study of disturbances of the gastrointestinal tract which have made this one of the foci of medical progress. It would probably be true to say that as much, or more, is known about the mechanism of absorption of vitamin $B_{12}$ by the cells of the intestine as of that of any other food principle and that a new salient of knowledge has been opened by the studies of pernicious anaemia which $I$ have been discussing in this lecture.

\section{REFERENCES}

Abels, J. (1959). Instrinsic factor van Castle en resorptie van vitamine $B_{12}$. V.R.B., Groningen.

Ackroyd, J. F. (1949). Clin. Sci., 7, 249.

- (1955). Brit. med. Bull., 11, 28

Allcock, E. (1961). Gastroenterology, 40, 81.

Alstead, S. (1949). Lancet, 1, 171 .

Ashby, W. (1919). J. exp. Med., 29, 267.

Asher, R. (1959). Lancet, 2, 417

Aufderheide, A. C. (1960). Amer. J. clin. Path., 34, 258

Badenoch, J. (1960). Brit. med. J., 2, 879, 963.

Bailey, N. T. J. (1957). The Mathematical Theory of Epidemics. Griffin, London.

Baldini, M., and Pannacciulli, I. (1960). Blood, 15, 614.

Belcher, E. H., and Hughes Jones, N. C. (1960). Clin. Sci., 19, 657 .

Berlin, N. I., Waldmann, T. A., and Weissman, S. M. (1959). Physiol. Rev., 39, 577.

Berlin, R., Berlin, H., Brante, G., and Sjöberg, S.-G. (1958). Acta med. scand., 162, 317.

Beutler, E., Drennan, W., and Block, M. (1954). J. Lab. clin. Med., 43, 427.

Blackburn, E. K., Cohen, H., and Wilson, G. M. (1955). Brit. med. J., $2,461$.

Bomford, R. R. (1946). Ibid., 2, 996.

Booth, C. C., and Mollin, D. L. (1959). Lancet, 1, 18

Bothwell, T., H., Callender, S., Mallett, B., and Witts, L. J. (1956). Brit. J. Haematol., $2,1$.

Hurtado, A. V., Donohue, D. M., and Finch, C. A. (1957). Blood, 12, 409.

Broquist, H. P. (1956). J. Amer. chem. Soc., 78, 6205.

Brown, G. M., Hayward, O. C., Powell, E. O., and Witts, L. J. (1944). J. Path. Bact., 56, 81.
Callender, S. T., Retief, F. P., and Witts, L. J. (1960). Gut, 1, 326.

Witts, L. J., Allison, P. R., and Gunning, A. (1961).

Cameron,, 2., G., Watson, G. M., and Witts, L. J. (1949). Blood, 4, 793, 803 .

Castle, W. B. (1959). Gastroenterology, 37, 377. Townsend, W. C., and Heath, C. W. (1930). Amer. J. med. Sci., 180, 305.

Chanarin, I., Dacie, J. V., and Mollin, D. L. (1959). Brit. J. Haematol., 5, 245.

Coombs, R. R. A., Mourant, A. E., and Race, R. R. (1945). Brit. exp. Path., 26, 255.

Cooper, B. A., and Castle, W. B. (1960). J. clin. Invest., 39, 199.

Dacie, J. V. (1960). The Haemolytic Anaemias, 2nd ed., vol. 1. Churchill, London.

- Smith, M. D., White, J. C., and Mollin, D. L. (1959). Brit. J. Haematol., 5, 56.

Doscherholmen, A., Finley, P. R., and Hagen, P. S. (1960). J. Lab. clin. Med., 56, 547.

and Hagen, P. S. (1959). Ibid., 54, 434.

Ellenbogen, L., and Williams, W. L. (1960). Biochem. biophys. Res. Comm., 2, 340.

- and Lichtman, H. C. (1960). Brit. med. J., 2, 1066. Evans, R. S., Takahashi, K., Duane, R. T., Payne, R., and Liu, C.-K. (1951). Arch. intern. Med., 87, 48.

Faber, K. (1895). Hospitalstidende, 38, 601. D. M., and Reiff, R. H. (1956). Blood, 11, 807.

Fox, H. J., and Castle, W. B. (1942). Amer. J. med. Sci., 203. 18.

Giblett, E. R., Coleman, D. H., Pirzio-Biroli, G., Donohue, D. M., Motulsky, A. G., and Finch, C. A. (1956). Blood, 11, 291 .

Girdwood, R. H. (1953). Lancet, 2, 53.

(1960). Advanc. clin. Chem., 3, 235.

Glass, G. B. J., Boyd, L. J., and Stephanson, L. (1954). Science, 120, 74.

Glynn, L. E., Holborow, E. J., and Johnson, G. D. (1957). Lancet, 2, 1083.

Gordon, A. S. (1959). Physiol. Rev., 39, 1.

Gräsbeck, R. (1960). Advanc. clin Chem., 3, 299.

- Runeberg, L., and Simons, K. (1959). Acta physiol. scand.,

Grinstein, M., Bannerman, R. M., Vavra, J. D., and Moore, C. V. (1960). Amer. J. Med., 29, 18.

Harrington, W. J., Minnich, V., Hollingsworth, J. W., and Moore, C. V. (1951). J. Lab. clin. Med., 38, 1.

Heatley, N. G., Jennings, M. A., Florey, H., Watson, G. M., Turnbull, A., Wakisaka, G., and Witts, L. J. (1954). Lancet, $2,578$.

Sheikh, M. A., and Taylor, K. B. (1960). Biochem. J. 76, 342 .

Heilmeyer, L. (1959). Dtsch. med. Wschr. 84, 1761.

Herbert, V. (1961). J. clin. Invest., 40, 8i.

Huff, R. L., Hennessy, T. G., Austin, R. E., Garcia, J. F., Roberts, B. M., and Lawrence, J. H. (1950). Ibid., 29, 1041.

Johns, D. G., Sperti, S., and Burgen, A. S. V. (1961). Canad. med. Ass. J., 84, 77

Keuning, F. J., Arends, A., Mandema, E., and Nieweg, H. O. (1959). J. Lab. clin. Med., 53, 127.

Knowles, J. P., Prankerd, T. A. J., and Westall, R. G. (1960). Lancet, 2, 347.

Lajtha, L. G., and Oliver, R. (1960). Ciba Foundation Symposium on Haemopoiesis, edited by G. E. W. Wolstenholme and M. O'Connor, p. 289. Churchill, London.

Landboe-Christensen, E.., Berk, L., and Castle, W. B. (1952). Amer. J. med. Sci., 224, 1.

Amer. med. Sci. 224, (1947). Acta med. scand., 127, 116

二 and Bohn, C. L. S. (1947) Acta med. scand.̈1 127, 116. scand., Suppl. 105, p. 104.

and Plum, C. M. (1948). Amer. J. med. Sci., 215, 17.

- and Wandall, H. H. (1953). Acta med. scand., 144, 467.

London, I. M., and West, R. (1950). J. biol. Chem., 184, 359.

Meulengracht, E. (1934). Acta med. scand., 82, 352.

Meulengracht, E. (1934).

(1939). Amer. J. med. Sci., 197, 201.

(1952). Acta med. scand., 143, 207

(1953). Ibid., 144, 290.

- and Schiødt, E. (1934). Ibid., 82, 375

Minot, G. R., and Murphy, W. P. (1926). J. Amer. med. Ass., 87,470 .

Moeschlin, S. (1958). In Sensitivity Reactions to Drugs, edited by M. L. Rosenheim and R. Moulton, p. 77. Blackwell, Oxford.

Mollison, P. L. (1956). Blood Transfusion in Clinical Medicine, 2nd ed., p. 170. Blackwell, Oxford.

Morgan, W. T. J., and Watkins, Winifred M. (1959). Brit. med. Bull., 15. 109.

Paulson, M.; and Harvey, J. C. (1954). J. Amer. med. Ass., 156, 1556.

Platt, B. S., and Webb, R. A. (1946). Proc. Nutr. Soc., 4, 132.

Polland, W. S. (1933). Arch. intern. Med., 51, 903.

Pollycove, M. (1959). In Eisenstoffwechsel, edited by W. Keiderling, p. 20. Thieme, Stuttgart. 
Rasch, C. A., Cotton, E. K., Griggs, R. C., and Harris, J. W. (1958). J. Lab. clin. Med., 52, 938 .

Reynell, P. C., Spray, G. H., and Taylor, K. B. (1957). Clin. Sci., 16, 663.

Salera, U., Tamburino, G., and Magnanelli, P. (1957). Sci. med. ital., 6, 179

Schiødt, E. (1938). Acta med. scand., 95, 49.

Schwartz, M., Lous, P., and Meulengracht, E. (1958). Lancet, 2. 1200 .

Sheeky, T. W., Rubini, M. E., Baco-Dapena, R., and PerezSantiago, Ë. (1960). Blood, 15, 761

Shemin, D., and Rittenberg, D. (1946) J. biol. Chem., 166, 627.

Silverman, M., Gardiner, R. C., and Condit, P. T. (1958). J. Nat. Cancer Inst., 20, 71 .

Spray, G. H., Fourman, P., and Witts, L. J. (1951). Brit. med. J., 2,202 .

- and Witts, L. J. (1953). Clin Sci., 12, 391.

- (1959). Lancet, 2, 702

Stohlman, F. (1959). The Kinetics of Cellular Proliferation, p. 318. Grune and Stratton, New York and London.

Sturgis, C. C., and Isaacs, R. (1929). J. Amer. med. Ass., 93, 747.

Taylor, K. B., and Morton, J. A. (1958). Lancet, 1, 29.

- (1959). J. Path. Bact., 77, 117.

Ternberg, J. L., and Eakin, R. E. (1949). J. Amer. chem. Soc. 71, 3858

Uotila, U. (1938). Acta med. scand., 95, 415.

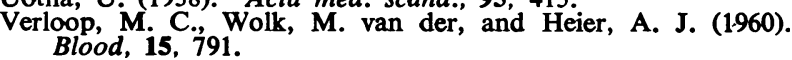

Watson, G. M., and Florey, H. W. (1955). Brit. J. exp. Path., 36, 479.

Wilkinson, J. F. (1930). Brit. med. J., 1, 236.

- (1949). Lancet, 1, 249, 291, 336

Klein, L., and Ashford, C. A. (1938). Quart. J. Med. 31, 555 .

Witts, L. J. (1932). Lancet, 1, 495.

- (1950). Irish J. med. Sci., 6, 315.

(1956). Anaemia and the Alimentary Tract. Royal College of Physicians, Edinburgh.

of 1959 . Canad

- (1960). Acta haemat (Basel), 24, 1.

\section{GUANETHIDINE IN TREATMENT OF HYPERTENSION}

BY

G. E. BAUER, M.R.C.P.

F. J. T. CROLL, M.R.A.C.P.

R. B. GOLDRICK, M.B., B.S.

D. JEREMY, M.R.A.C.P.

J. RAFTOS, M.R.A.C.P.

H. M. WHYTE, M.R.C.P.

AND

A. A. YOUNG, M.R.A.C.P.

From the Cardiovascular Clinic, Sydney Hospital

Effective blood-pressure control in severe hypertension was first made possible with the introduction of hexamethonium by Paton and Zaimis in 1948. The impetus to this discovery came from our surgical colleagues, who during the preceding two decades had shown that ablation of part of the sympathetic nervous system resulted, in some instances, in remarkable falls in blood-pressure. Hexamethonium, the first ganglionblocking agent of practical value, was succeeded by pentolinium, chlorisondamine, mecamylamine, and pempidine, the introduction of each of these compounds representing an advance in therapy, particularly in respect to improved gastro-intestinal absorption, more uniform blood-pressure control, and some diminution in side-effects.

Ganglion-blocking therapy with these drugs was accompanied, when given in adequate therapeutic doses, by symptoms of parasympathetic blockade such as blurred vision, dryness of the mouth, severe gastrointestinal disturbances, difficulty in micturition, and impotence. These pharmacological side-effects were largely responsible for restricting treatment with these drugs to the severest types of hypertension.

Great strides were made in 1959 with the synthesis of two new compounds which for the first time made good postural blood-pressure control, with selective sympathetic inhibition and without parasympathetic inhibition, a practical proposition. Bretylium tosylate was introduced in Great Britain by Boura et al. (1959), and has since been evaluated in many different parts of the world. Guanethidine sulphate, the second compound and the subject of this communication, has been available for a comparable period of time and has been shown to differ from bretylium in a number of important aspects.

It has been our custom at the cardiovascular clinic, Sydney Hospital, to report experiences with new ganglion-blocking agents such as pentolinium (Bauer, 1955), chlorisondamine (Bauer et al., 1957), mecamylamine (Bauer et al., 1959), pempidine (Croll et al., 1961), and bretylium (Bauer, 1961). We now wish to record our impressions of guanethidine after treating 28 patients for a period of up to 12 months.

\section{Pharmacology}

Guanethidine sulphate is the generic name for [2-(octahydro-1-azocinyl)-ethyl]-guanethidine sulphate, which was synthesized by Maxwell et al. (1959).

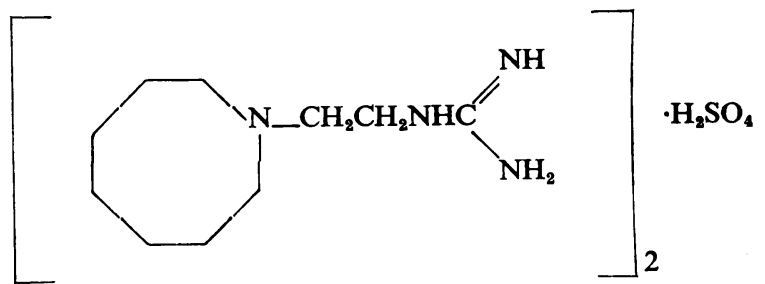

Its discovery arose from a fortuitous observation by the same workers that experimental animals treated with a synthetic compound, hexahydro-1-azepinepropionamidoxime hydrochloride (Su-4029), several days earlier failed to respond with the usual pressor action after injection of amphetamine. Subsequently they demonstrated that this same compound, Su-4029, produced a profound and protracted antihypertensive action in renal and neurogenic hypertensive dogs. Clinical trials in human subjects were, however, disappointing. Several compounds related to Su-4029 were next studied and guanethidine sulphate proved to be the most promising. Unlike its predecessor, guanethidine sulphate elicited delayed, profound, and prolonged relaxation of the nictitating membranes in dogs and cats, giving clear indication of interference with the functioning of the sympathetic nervous system.

Pharmacological experiments with this drug may be summarized as follows. (1) Coupled with the relaxant action of the nictitating membrane, guanethidine exerts a marked and prolonged antihypertensive action in unanaesthetized renal and neurogenic hypertensive dogs. (2) Preganglionic stimulation of efferent sympathetic nerves in animals treated with guanethidine fails to elicit normal responses from smooth-muscle effectors, indicating blockade somewhere in the efferent sympathetic nervo-smooth-muscle effector complex. (3) Guanethidine does not suppress but rather augments the response of the effector organs to injected noradrenaline, suggesting that the blocking action is exerted within the nerve and not within the smooth muscle. Patients with hypertension due to phaeochromocytoma may develop a marked pressor response to guanethidine. 